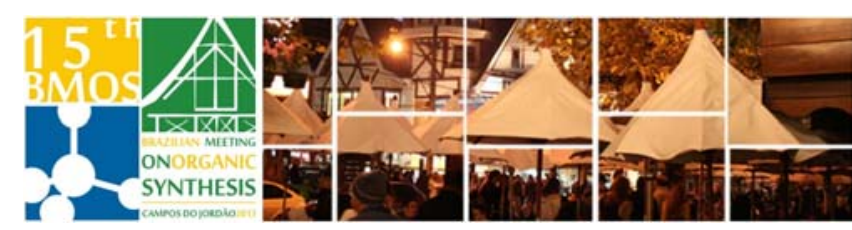

\title{
Selective estragole to trans-anethole isomerization in ionic liquids
}

\author{
Bárbara Leal, ${ }^{*}$ Alessandra Pazini and Jairton Dupont \\ Laboratory of Molecular Catalysis, Institute of Chemistry, UFRGS, Avenida Bento Gonçalves, 9500, Porto \\ Alegre, 91501-970 RS Brazil \\ *barbara.leal@ufrgs.br
}

Keywords: estragole, isomerization, ruthenium

\section{INTRODUCTION}

Trans-anethole is a naturally-occurring product which has been traditionally extracted from anise or fennel oils, albeit with variable proportions of its cisisomer as an impurity. ${ }^{1}$ However, the increasing demand of trans-anethole has made extraction from natural sources not sufficient to supply the market, hence the need to produce it synthetically. Effectively, only trans-anethole is interesting for industry since the cis-isomer presents a higher toxicity and unpleasant organoleptic properties. Consequently, the search for efficient and selective catalytic systems able to promote the estragole to trans-anethole isomerization still remains a challenge for synthetic chemists.

\section{RESULTS AND DISCUSSION}

Initially, the catalytic activity of complexes $\mathrm{PdCl}_{2}(\mathrm{NCPh})_{2} \quad$ (1a), $\quad \mathrm{RhCl}\left(\mathrm{PPh}_{3}\right)_{3} \quad$ (1b) and RuHClCO $\left(\mathrm{PPh}_{3}\right)_{3}$ (1c) in the isomerization of estragole has been tested. Experiments were performed at $80{ }^{\circ} \mathrm{C}$ using $2 \mathrm{mmol}$ of substrate, $0.020 \mathrm{mmol}$ of complex, $0.5 \mathrm{~mL}$ of toluene (1a and 1c) or ethanol (1b), and the reaction was monitored by GC analyses of aliquots. The best results were obtained with 1c which quantitatively converted estragole into anethole in $1 \mathrm{~h}$ with selectivity in the trans isomer of $95 \%$. We next investigated how the process is affected by changing the catalyst loading. We observed that decreasing the amount of ruthenium (complex 1c) from 0.020 to $0.015 \mathrm{mmol}$ did not modify the trans:cis ratio (95:5). On the other hand, lower metal loadings $(0.010 \mathrm{mmol})$ conduced to lower selectivities in the desired trans-isomer $(92 \%)$. In an attempt to improve the selectivity, the process has been carried out at lower temperature $\left(35{ }^{\circ} \mathrm{C}\right)$ with the most active complex 1c. The transselectivity decreased $(81 \%$ vs. $95 \%)$ and the reaction time dramatically increased ( $7 \mathrm{~h}$ vs. $1 \mathrm{~h}$ ). The isomerization of estragole has also been tested in different amounts of toluene $(0.5,1.0$ and $4.0 \mathrm{~mL})$. Remarkably, complete conversion in only 5 min was observed when $0.5 \mathrm{~mL}$ of toluene was employed, with high selectivity in trans-anethole (98\%).

The next step was the employment of ionic liquids in the estragole isomerization in order to obtain a simple separation of products from the reactional media. Experiments were performed at $80{ }^{\circ} \mathrm{C}$ using $2 \mathrm{mmol}$ of substrate, $0.015 \mathrm{mmol}$ of $1 \mathrm{c}, 0.5 \mathrm{~mL}$ of toluene and $0.5 \mathrm{~mL}$ of $\mathrm{BMI} \cdot \mathrm{NTf}_{2}$. A conversion of $99 \%$ was obtained after 20 min with trans-selectivity of only $87 \%$. Then, ionophilic ligands (Figure 1) were applied in this system to support the catalyst in the ionic phase and allow its recyclability.

Figure 1. Ionophilic ligands employed in isomerization.

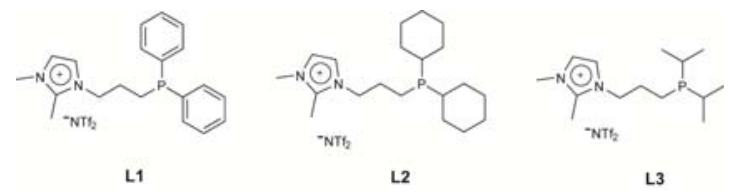

The system containing only $\mathrm{BMI} \cdot \mathrm{NTf}_{2}$ has decreased its conversion by reuse of catalytic phase $\left(99 \% 1^{\text {st }}\right.$ cycle; $50 \% 2^{\text {nd }}$ cycle; $32 \% 3^{\text {th }}$ cycle; $22 \% 4^{\text {th }}$ cycle), although the selectivity in trans-anethole remains unchanged (87\%). Gratifyingly, the system containing the ionophilic ligands (L1, L2 or L3) could be re-used up to three consecutive runs without loss of conversion (>99.5\%) and selectivity (96\%). However, a decrease of the conversion (>99.5\% vs. $91 \%$ ), accompanied by a slight loss of the transselectivity ( $96 \%$ vs. $91 \%$ ), was observed after the fourth cycle.

\section{CONCLUSION}

In summary, the RuHCICO$\left(\mathrm{PPh}_{3}\right)_{3}$ has shown to be effective catalyst to convert estragole into anethole. The best conversion (>99.5\%) and selectivity toward trans-anethole (98\%) were obtained with $0.015 \mathrm{mmol}$ of this precursor, $0.5 \mathrm{~mL}$ of toluene, $80{ }^{\circ} \mathrm{C}$ and $5 \mathrm{~min}$ of reaction. Furthermore, the system containing BMI.NTf $\mathrm{NT}_{2}$ and ionophilic ligands showed to be a good alternative to recycle the catalyst with high conversions $(>99.5 \%)$ and high trans-selectivities (96\%).

\section{ACKNOWLEDGEMENTS}

Thanks are due to the following agencies for financial support: CNPq, CAPES and PETROBRAS.

\section{REFERENCES}

${ }^{1}$ Lastra-Barreira, B. and Crochet, P. Green Chem. 2010, 12, 1311.

2 Lastra-Barreira B.; Francos, J.; Crochet, P. and Cadierno V. Green Chem. 2011, 13, 307.

$15^{\text {th }}$ Brazilian Meeting on Organic Synthesis - 15 ${ }^{\text {th }}$ BMOS - November 10-13, 2013 - Campos do Jordão, Brazil 